\title{
TESTING OF V3.SUN MODULE PROTOTYPE FOR SOLAR RADIATION MODELLING ON 3D OBJECTS WITH COMPLEX GEOMETRIC STRUCTURE
}

\author{
J. Kaňuk ${ }^{1}$ *, S. Zubal ${ }^{2}$, J. Šupinský ${ }^{1}$, J. Šašak ${ }^{1}$, M. Bombara ${ }^{3}$, V. Sedlák ${ }^{1}$, M. Gallay ${ }^{1}$, J. Hofierka ${ }^{1}$, K. Onačillová ${ }^{1}$ \\ ${ }^{1}$ Institute of Geography, Faculty of Science, Pavol Jozef Šafárik University in Košice, Slovakia - (jan.kanuk, jozef.supinsky, \\ jan.sasak, vladimir.sedlak, katarina.onacillova, jaroslav.hofierka, michal.gallay)@upjs.sk \\ ${ }^{2}$ Moon-Soft, s.r.o., B. Němcovej 2349/2, Trebišov 07501 - stano.zubal@moon-soft.eu \\ ${ }^{3}$ Institute of Physics, Faculty of Science, Pavol Jozef Šafárik University in Košice, Slovakia - marek.bombara@upjs.sk
}

Commission VI, WG VI/10

KEY WORDS: v3.sun, solar radiation modelling, 3D data, TIN

\begin{abstract}
:
High-resolution solar radiation modelling requires the three-dimensional geometric structure of the landscape to be respected. Currently, remote sensing methods such as laser scanning and close-range photogrammetry are most commonly used for detailed mapping. The output is detailed 3D models containing buildings, trees, relief and other landscape features. The raster approach allows modeling solar energy for relief, but it is unsuitable for landscape objects such as buildings and trees. The polygonal features vector approach is mainly designed for buildings. Our goal is to create a freely available tool for highly detailed solar radiation modelling for geometrically complex 3D landscape objects. In the paper, we present a prototype of the v3.sun module. We propose a solution of solar radiation modeling designed for all landscape features based on TIN data structure. In the paper, tests of the proposed algorithmic solution for various types of 3D data obtained from the above-mentioned collection methods are demonstrated.
\end{abstract}

\section{INTRODUCTION}

At present, solar radiation plays an important role in landscape planning and landscape management, which has a significant impact on the thermal and luminous comfort of buildings and the life quality of people in cities. Quantification of the amount of solar radiation incident at user defined location is particularly needed when exploring natural processes such as biomass growth potential (Milne et al., 1992) and photobiology (Muneer, 2007) or for planning specific human activities such as energy buildings (Xu et al., 2012), photovoltaic potential (Šúri et al., 2007) etc. The essence of solar radiation modelling is the mathematical expression of all the factors that act on the sunbeam when passing through the atmosphere to the impact on the area under consideration (Mousazadeh et al., 2007).

The general formula of solar energy calculation can be expressed by the equation (Biljecki et al., 2015):

$$
I=\sum_{T_{0}}^{T_{i}} f\left\{([\varphi, \lambda, h], \tau, \alpha, A,[w]) . \Delta t_{i}\right\}
$$

Where $\mathrm{I}=$ solar irradiation

$\mathrm{T}_{0}=$ start time

$\mathrm{T}_{\mathrm{i}}=$ end time

$\Delta t_{i}=$ the duration of the $i^{\text {th }}$ time interval

$[\varphi, \lambda, h]=$ latitude, longitude, elevation of the surface

$\tau=$ slope vector normal

$\alpha=$ azimuth vector normal

$\mathrm{A}=$ area conditions

$[\mathrm{w}]=$ other components such as meteorological

\footnotetext{
* Corresponding author
}

Several papers have been devoted to the calculation of the solar energy incident on differently oriented surfaces, e.g. Kasten and Young (1989) and Kasten (1996), Krcho (1990), Kittler and Mikler (1986), Littlefair (2001), Pereira et al. (2001) and many others. Thus, the accuracy of the solar radiation modelling result depends mainly on the input data. With a high degree of precision, we can obtain data representing the geometric structure of the landscape (terrain, buildings, vegetation, etc.). However, we can only define atmospheric conditions with a certain degree of uncertainty (cloudiness, aerosols, etc.). Although the mapping method of the country has changed in recent years, the principle of solar energy calculation remains steady.

To automate the calculation of solar radiation, a number of tools have been proposed that have been mostly implemented in the Geographic Information System (GIS) such as Solar Analyst in ArcGIS (Esri, 2019), Potential Incoming Solar Radiation Tool designed for SAGA GIS (Conrad et al., 2015), r.sun model (Hofierka and Š́ri, 2004) and v.sun (Hofierka and Zlocha, 2012) for GRASS GIS (Neteler and Mitasova, 2004). There are also solar modelling tools that are not implemented in GIS such as Solarradiation.m designed for MatLAB (Kumar et al., 1997), CFD simulation tools designed for solar radiation modelling, as well as modules designed by CAD software such as Shadow Analyst in Google Sketch Up, Solar Analysis for Revit and many more. Biljecki et al. (2015) designed and implemented software prototype Solar3Dcity, which supports data stored according to the OGC standard CityGML.

The common feature of the software mentioned above is that input data for solar radiation modelling are vector polygons or 
raster data. In particular, these tools have been designed for data representing a terrain (raster) or buildings (vector polygons) derived from data obtained by tachymetry, GNSS measurement and aerial photogrammetry. Alternatively, CAD tools for solar radiation modelling are designed for polygon vector data handdrawn by architects and designers. Currently, photogrammetry and laser scanning are the most widely used methods for data acquisition of the landscape geometric structure, the output of which is dense point clouds representing landscape features (Luhmann et al., 2007; Vosselman and Maas, 2010). From these point clouds, 3D models of the landscape based on TIN data structure are derived, which are input data for further modelling of landscape processes, including solar radiation. In addition, the solar radiation modelling is becoming increasingly demanding on quality and speed of generation of 3D models. At present, however, it is not possible to model solar radiation simultaneously for relief, buildings, trees and other landscape objects. The aim of the paper is to demonstrate the prototype of the v3.sun module, which is designed for data structures derived through adaptive triangulation methods from point cloud for solar radiation modelling. The main advantage of this approach is that, we get a more comprehensive solar radiation analysis of the landscape. A complex 3D landscape model is used to take into account the impact of one landscape feature on another (e.g., terrain on buildings, vegetation on building, vegetation on terrain), which has not been possible yet.

\section{DATA AND METHODS}

The presented prototype of v3.sun module is designed for a triangulated irregular network (TIN) derived from a point cloud that can represent a landscape objects in high spatial resolution and is not limited by the complexity of features geometry. Our goal is to create a freely available tool for highly detailed solar radiation modelling for geometrically complex 3D landscape objects. We undertook this study with an intention of further implementation of the tool in the Open-Source GRASS GIS environment. In this paper, we focus on introducing a methodological framework and testing calculations through a series of operations using GRASS Shell Scripts (Figure 1).

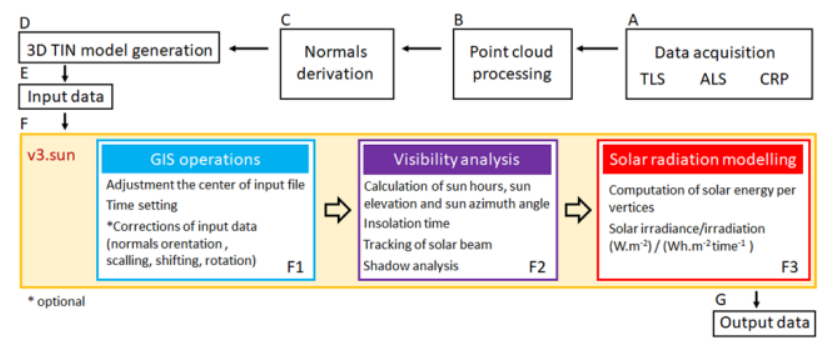

Figure 1. Methodological framework of solar radiation modelling proposed for $\mathrm{v} 3$.sun module prototype.

\subsection{Data acquisition methods}

In our paper, we are testing an algorithm for solar radiation modelling for 3D models of an identical area derived from the three most commonly used methods of landscape geometry mapping. These are close-range photogrammetry (CRP) (Figure $2 \mathrm{~A}$ ), airborne laser scanning (ALS) (Figure $2 \mathrm{~B}$ ), and terrestrial laser scanning (TLS) (Figure $2 \mathrm{C}$ ).

As a test area, we chose a building located in a vineyard with surrounding trees slightly on the slope. This is an area of $50 \mathrm{~m} \mathrm{x}$
$30 \mathrm{~m}$, with $48.440189 \mathrm{~N}$ and $21.703352 \mathrm{E}$ coordinates of projection center of the test area.

Data collection for the derivation of a 3D landscape model by CRP was realized with the DJI Phantom 4 Pro. The flight was undertaken at a height of $50 \mathrm{~m}$ AGL with orthogonal orientation of the camera. Side and front overlap ratio of photos was $70 \%$ and speed of the platform was $10 \mathrm{~m} \cdot \mathrm{s}^{-1}$.

In the case of data collection using TLS, we used the Riegl VZ1000 scanner device. Object of interest was mapped from 6 scan positions. We carried out TLS using Panorama 60 mode at a scanner range of $450 \mathrm{~m}$, which means that the scanner emitted a laser pulse to the ambient environment at a vertical and horizontal rotation of the mirror every 0.06 degrees at a scanning frequency of $300 \mathrm{kHz}$.

For ALS mapping, we used SCOUT B1-100 unmanned aerial system with integrated VUX1 laser scanner from Riegl (Kaňuk et al., 2018).Flight altitude was 70 meters AGL and speed of aircraft was $3 \mathrm{~m} . \mathrm{s}^{-1}$. The scanner frequency was $550 \mathrm{kHz}$ and the study area was scanned in 2 flight lines in SE and NW direction. All measurement work was done on October 12, 2018, within about 5 hours, to eliminate the effect of changing the geometry of landscape elements on the results of solar radiation modelling.

The mapping resulted in point clouds representing the terrain, building, trees and part of the vineyard. Agisoft Photoscan software was used to generate point cloud from CRP, RiProcess software for ALS, and RiScan Pro software for TLS. Generated point clouds were placed in the S-JTSK coordinate system (EPSG code 5514) and height system Bpv (Balt after settlement).

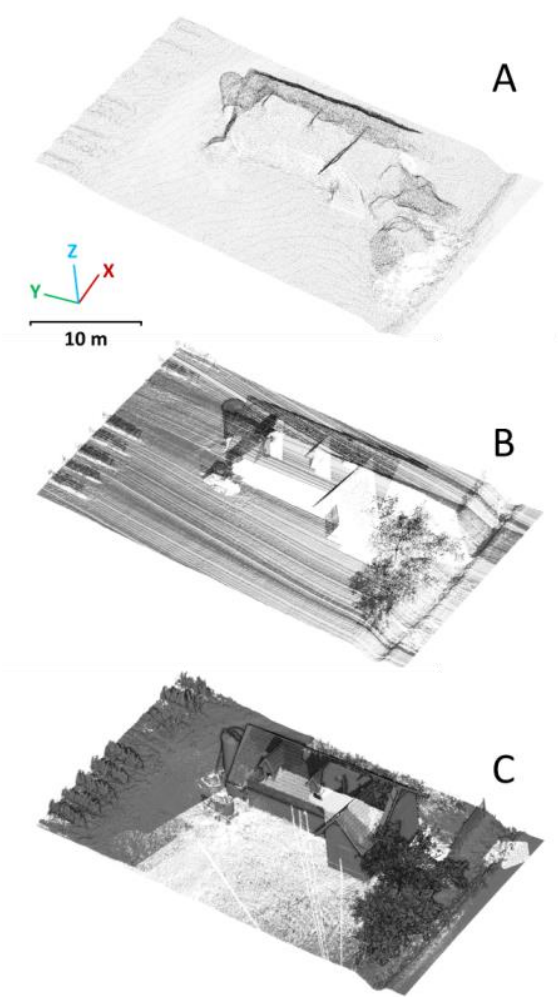

Figure 2. Point cloud derived from different remote sensing methods - (A) close-range photogrammetry, (B) airborne laser scanning (ALS), terrestrial laser scanning (TLS). 


\subsection{D models derivation and input data preparation}

3D models of the area of interest were derived from the point clouds using an interpolation method based on adaptive triangulation method (Figure 1D). We used 3D Delaunay triangulation implemented in Geomagic Wrap software (Edelsbrunner et al., 1998) to create 3D models. To build a TIN, it is necessary to orient the normals of the vertices of the triangles to the sun (Figure $1 \mathrm{C}$ ). Determining the orientation of normals of the triangles plays a key role in preparing input data for modelling solar radiation distribution. Other interpolation methods available in open source tools such as Poisson Surface Recontruction (Kazhdan and Hoppe, 2013) or Ball-pivoting (Bernardini et al., 1999) can also be used to derive 3D models from a point cloud. In this case, the input point cloud must have correctly determined the orientation of the normals before the surface reconstruction, which in some cases is a challenging task due to the inhomogeneous distribution of the points. If the orientation of normals of the triangles have been directed away from the sun, within the v3.sun module can be set to be inverted (Figure 1 F1). The v3.sun module is designed for small territories in order to model in detail the distribution of solar energy flow for high spatial resolution input data regardless of the geometric complexity of objects such as buildings and vegetation. To simplify the calculation, the solar radiation is calculated for the input data in the local coordinate system in which the coordinates are expressed in meters. If the scaling, shifting and rotation of objects were incorrectly determined when converting data from a global coordinate system to a local coordinate system, we also implemented the possibility of correcting them for the v3.sun module (Figure 1 F1).

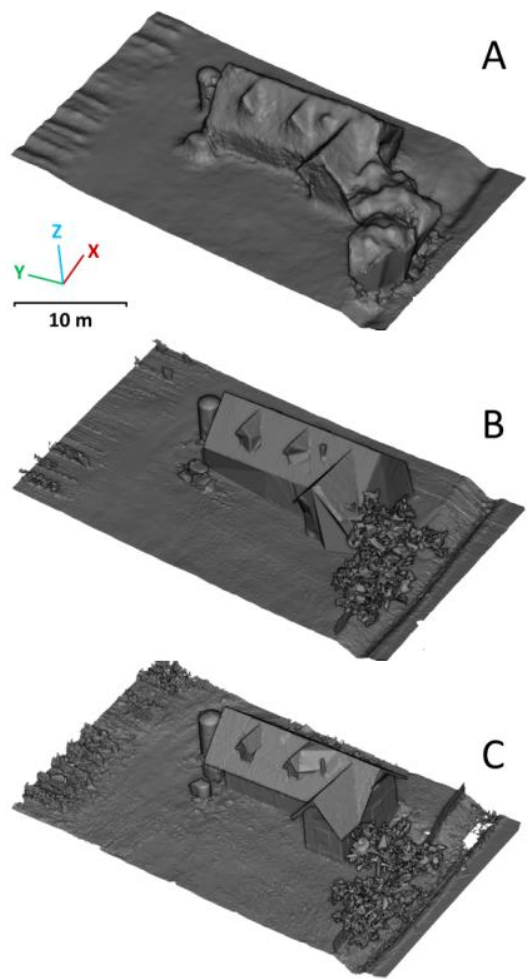

Figure 3. 3D TIN model derived from (A) CRP, (B) ALS, (C) TLS point cloud with correctly determined the orientation of the normals.

\subsection{Proposed approach to solar radiation modelling via v3.sun module prototype}

The input for solar radiation modelling is the TIN model in ASCII format "*.ply". The input file has defined $\mathrm{x}, \mathrm{y}$, and $\mathrm{z}$ coordinates for each vertex, and a normal orientation (Figure 3 ). The basic condition for the calculation of solar irradiance/irradiation is that all faces must be triangles. The proposed v3.sun module allows to perform irradiance/irradiation calculations for user-defined time/time interval (Figure 1, F1). After loading the input data, the sun elevation and sun azimuth angle are calculated. In the case of calculation of irradiation, the position of the sun is determined according to a defined step within the astronomical day (Figure 1, F2). Subsequently a tracking solar beam for each face of triangle is performed. The result is stored in the "energy" parameter as $\mathrm{J} / \mathrm{m}^{2}$ (joule per square meter). Thus, it is the amount of energy that has impacted the area of the face of triangle. For the calculation of solar radiation via the v3.sun module, the same equations were used as in the r.sun module presented in Hofierka and Šúri (2004). However, in this version of the v3.sun module, sunlight is not automatically attenuated by passing through the atmosphere. The proposed algorithm is only for calculating the direct component of solar radiation, thus it does not include the diffuse and reflected component of solar radiation (Figure 1, F3).

\section{RESULTS}

\subsection{Validation v3.sun module prototype using r.sun module}

After designing the algorithm of the v3.sun module, first we tested the modelling of direct composition of solar radiation on a sample of data from a high mountain environment. As an example, we used part of the territory of the High Tatras in the Carpathians. This is an area of $4 \mathrm{~km} \mathrm{x} 4 \mathrm{~km}$ with the coordinates of the centre projection of $49^{\circ} 10^{\prime} 38.4^{\prime \prime} \mathrm{N}$ and $20^{\circ} 10^{\prime} 54.6 " \mathrm{E}$. The source of the data was the ALS point cloud provided by Geodetic and Cartographic Office of the Slovak Republic. The reason was to compare the results of the calculation for DTM derived from the point cloud from ALS, because we want to validate the results of solar radiation modelling using the proposed $\mathrm{v} 3$.sun module with respect to the r.sun model, which is designed for raster representation. As mentioned above, the relief can be expressed by a raster data model. However, raster data are limited to modelling landscape feature with complex geometric structures such as buildings and trees. The proposed v3.sun module is designed for all types of landscape features regardless of the complexity of their geometric structure. Thus, the relief can also be expressed by the TIN data model. We assume that if the analysis of the solar energy distribution we will compare with the solar radiation modelling on the relief using the r.sun module for raster data and via the v3.sun module for the TIN data, it will be possible to validate the correctness of the proposed approach. We consider data from the alpine environment from vertically rugged territory to be suitable for testing solar radiation modelling for several reasons. On the one hand, it is a sufficiently morphologically rugged terrain that can be expressed using a raster and TIN model. So, we can compare results from r.sun and v3.sun module. On the other hand, the vertical and morphologically rugged environment makes it possible to test several capabilities of the proposed algorithm, such as taking into account adjacent geometric structures to model solar radiation (surrounding hills obscuring valleys) and 
significant changes in radiation energy in a small area caused by differently oriented and inclined slopes.

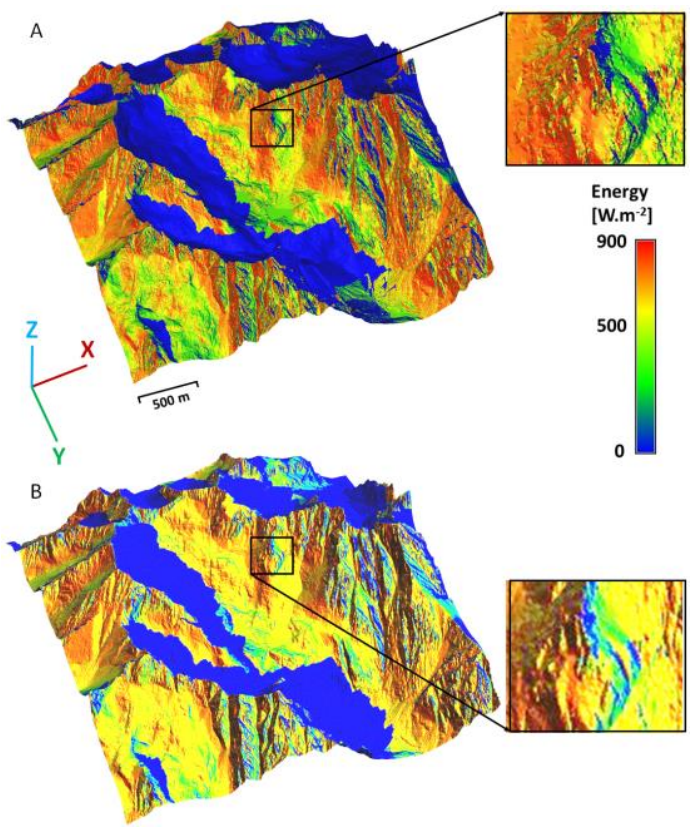

Figure 4. Solar radiation modelling for 15 September at 15 o'clock using (A) v3.sun module and (B) r.sun module. As input data of DTM were used (A) TIN model and (B) grid.

To model solar radiation, we used DTM in the form of a raster with a resolution of $2 \mathrm{~m}$ as an input. Using the r.slope.aspect tool implemented in GRASS GIS, we have derived the surface orientation raster with respect to azimuth directions and their slope. Subsequently, we simulated sunlight for 15 September at 15 o'clock. We used the same point cloud as the input data for the v3.sun module and derived a TIN model from it as is described in Figure 1. We also optimized the size of triangles to $2 \mathrm{~m}^{2}$. Although the geometric representation will be different for raster and TIN DTM in detail, it will be sufficient with respect to the size of the area and purpose of use.

We evaluated the results of solar radiation modelling in two ways. In the first step, we set the same color scale for both results. The lowest value in both cases was 0 (shaded area), the highest value was in the case of r.sun modelling of $889 \mathrm{~W} . \mathrm{m}^{-2}$ and $897 \mathrm{~W} . \mathrm{m}^{-2}$ for v3.sun modelling. We focused visually on the places where the shadows were calculated. Both modelling results are very similar, especially in small details. This is mainly due to the fact that in the case of the grid, the peaks of the mountains are modelled smoother, causing a different shading. In the second step, the energy values of the modelled solar radiation were statistically compared. We have converted TIN and grid to points and compared the values for individual points. $95 \%$ of the differences are less than $10 \%$ of the reference energy value (Figure 4). This is mainly related to the small differences of azimuth and orientation of the areas for which the solar energy distribution has been modelled. Since the TIN and GRID models were not identical, these differences are understandable. The remaining 5\% differences greater than $10 \%$ of the reference energy value compared are related to the overshadowing problem described above. We can conclude that the designed module v3.sun calculates the values of the solar flux energy correctly.

\subsection{Comparing modelling results from different input data types}

In this paper, we wanted to test the algorithm of v3.sun and its ability to deal with geometrically complex data from three different data sources (Figure 3) to model solar radiation. Since these are computationally demanding tasks, we used a 24-core server computing node to calculate the solar radiation distribution using the proposed algorithm.

In the case of the CRP data collection method, from 114,474 points we have created a TIN model containing more than 250,000 triangles. The calculation time of solar radiation modelling for data derived from CRP data was approximately 5 and a half minutes (Table 1. CRP). In the case of ALS, a TIN model of approximately 800,000 triangles was derived from more than 500,000 points. The calculation of the solar distribution lasted approximately 26 minutes (Table 1 . ALS). The greatest computational challenge was solar modelling for a TIN model containing approximately 1 million triangles derived from a point cloud of more than 4.5 million points. In this case, the calculation took approximately 42 and a half minutes (Table 1. TLS).

\begin{tabular}{|l|r|r|r|}
\hline Data type & \multicolumn{1}{|c|}{ CRP } & \multicolumn{1}{c|}{ ALS } & \multicolumn{1}{c|}{ TLS } \\
\hline & & & \\
Points & 114,274 & 515,503 & $4,606,275$ \\
Faces & 250,589 & 801,389 & 984,783 \\
Computing time & $5 \mathrm{~min} 23 \mathrm{~s}$ & $25 \mathrm{~min} 46 \mathrm{~s}$ & $42 \mathrm{~min} 22 \mathrm{~s}$ \\
\hline
\end{tabular}

Table 1. Selected parameters of the input data derived from the three measurements and comparing the calculation time

The result of modelling the distribution of solar radiation energy can be compared within Figure 5. The figure shows that the more detailed the model of input data, the more detailed approximation of solar radiation energy can be modelled. Thus, the module's v3.sun algorithm is not limited by the number of triangles, but especially by the computing power of the computer and the quality of the input data. 


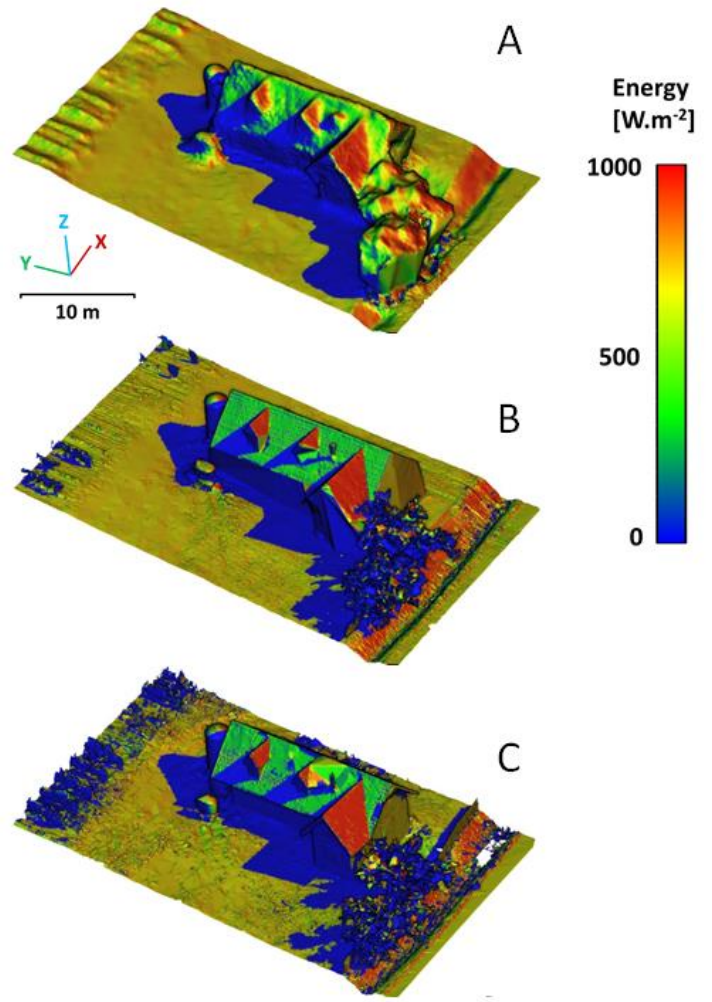

Figure 5. Solar radiation modelling for 15 September at 12 o'clock using 3D TIN model derived from (A) CRP, (B) ALS, (C) TLS

\subsection{Calculate irradiance/irradiation for user-defined time/time period}

The proposed algorithm for the v3.sun module works similarly to module v.sun (Hofierka and Zlocha, 2004) and r.sun (Šúri and Hofierka, 2004) in two modes.
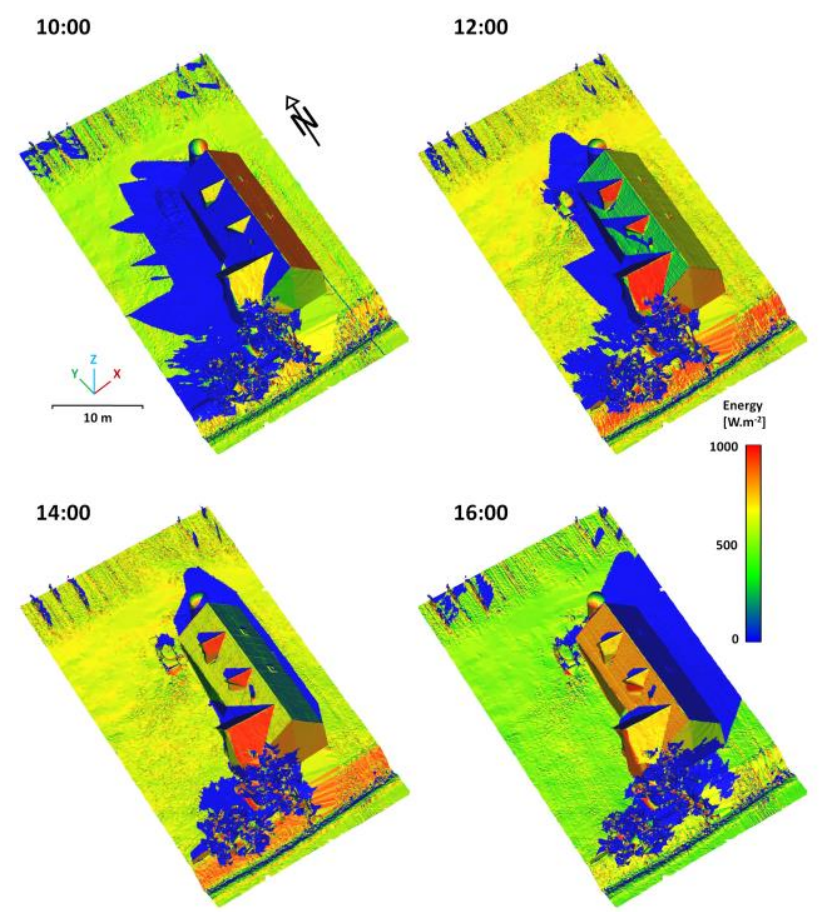

Figure 6. Calculation of solar irradiance for July 15 for a time moment at 10:00, 12:00, 14:00 and 16:00.

In the first mode, the user defines the date and time and then it is possible to calculate the irradiance expressed in $\mathrm{W} . \mathrm{m}^{-2}$ for a given time moment (Figure 6.). The second mode calculates for the user-defined irradiation time period expressed in $\mathrm{Wh} . \mathrm{m}^{-2}$ (Figure 7.).

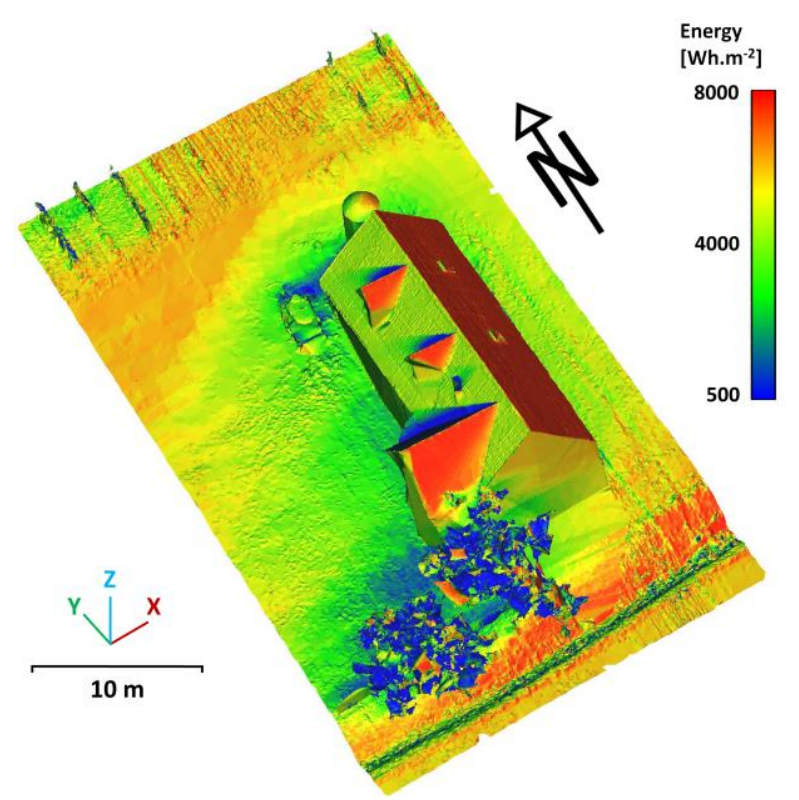

Figure 7. Irradiation calculation for July 15 for a time period from 08:00 to 18:00.

\section{CONCLUSION}

In this paper, we present a prototype of the v3.sun module for the calculation of solar energy distribution. This module is designed for open source GRASS GIS software. Nowadays, mainly remote sensing methods and techniques such as closerange photogrammetry, airborne laser scanning and terrestrial laser scanning are used to map the landscape. The main output of these methods are point clouds which represent all landscape objects. It is possible to derive a TIN model that represents the surface of the mapped objects from them. The main advantage of proposed v3.sun module is that it is able to calculate the solar energy distribution to all types of landscape features such as terrain, buildings, vegetation, regardless of the complexity of their geometric structure. The calculation of the solar energy distribution was validated with the r.sun module. We can say that the proposed algorithm calculates the solar energy values correctly. Irradiance/irradiation can be calculated for userdefined time/time period. In the presented paper, we demonstrated that the v3.sun module is designed in this form only to model the direct component of solar radiation. In the future, we would like to implement v3.sun in the GRASS GIS environment. Subsequently, additional functionality would be added in order to calculate all solar radiation components (direct, diffuse and reflected radiation). This assumes that the module will also be able to use other input data such as the amount of aerosols in the atmosphere, the albedo of surrounding surfaces, and others. 


\section{ACKNOWLEDGEMENTS}

With support by grants VEGA 1/0839/18 Development of a new v3.sun module designed for calculation of the solar energy distribution for digital geodat derived from a point cloud using adaptive triangulation methods and APVV/SK-CN-RD-180015: Key Technologies on the Integration of Multi-GNSS, LiDAR and Oblique Photogrammetry in 3D High-Quality Reconstruction of Smart City (3DSMARTCITY).

\section{REFERENCES}

Bernardini, F., Mittleman, J., Rushmeier, H., Silva, C., \& Taubin, G. 1999. The ball-pivoting algorithm for surface reconstruction. IEEE transactions on visualization and computer graphics, 5(4), 349-359.

Biljecki, F., Heuvelink, G. B., Ledoux, H., \& Stoter, J. 2015. Propagation of positional error in 3D GIS: estimation of the solar irradiation of building roofs. International Journal of Geographical Information Science, 29(12), 2269-2294.

Conrad, O., Bechtel, B., Bock, M., Dietrich, H., Fischer, E., Gerlitz, L., Wehberg, J., Wichmann, V. \& Böhner, J. 2015. System for automated geoscientific analyses (SAGA) v. 2.1. 4. Geoscientific Model Development, 8(7), 1991-2007.

Edelsbrunner, H., Facello, M. A., Fu, P., Qian, J., \& Nekhayev, D. V. 1998. Wrapping 3D scanning data. In Three-Dimensional Image Capture and Applications (Vol. 3313, pp. 148-159). International Society for Optics and Photonics.

Esri: Area Solar Radiation. ArcGIS for Desktop. http://desktop.arcgis.com/en/arcmap/10.3/tools/spatial-analysttoolbox/area-solar-radiation.htm. Accessed May 2019.

Hofierka, J., \& Zlocha, M. 2012. A New 3-D Solar Radiation Model for 3-D City Models. Transactions in GIS, 16(5), 681690.

Kaňuk, J., Gallay, M., Eck, C., Zgraggen, C., \& Dvorný, E. 2018. Technical report: Unmanned helicopter solution for survey-grade lidar and hyperspectral mapping. Pure and Applied Geophysics, 175(9), 3357-3373.

Kasten, F. 1996. The Linke turbidity factor based on improved values of the integral Rayleigh optical thickness. Solar energy, $56(3), 239-244$.

Kasten, F., \& Young, A. T. 1989. Revised optical air mass tables and approximation formula. Applied optics, 28(22), 4735-4738.

Kazhdan, M., \& Hoppe, H. 2013. Screened poisson surface reconstruction. ACM Transactions on Graphics (ToG), 32(3), 29.

Kittler, R., \& Mikler, J. 1986. Fundamentals of the solar radiation utilization. VEDA: Bratislava.

Krcho, J. 1990. Morphometric analysis and digital models of georelief. Veda, Bratislava, 432.

Kumar L, Skidmore AK and Knowles E. 1997. Modelling topographic variation in solar radiation in a GIS environment.
International Journal of Geographical Information Science 11(5), 475-497.

Littlefair, P. 2001. Daylight, sunlight and solar gain in the urban environment. Solar Energy, 70(3), 177-185.

Luhmann, T., Robson, S., Kyle, S., \& Harley, I. 2007. Close range photogrammetry. Wiley.

Milne, R., Sattin, M., Deans, J. D., Jarvis, P. G., \& Cannell, M. G. R. 1992. The biomass production of three poplar clones in relation to intercepted solar radiation. Forest Ecology and Management, 55(1-4), 1-14.

Mitasova, H., \& Neteler, M. 2004. GRASS as open source free software GIS: accomplishments and perspectives. Transactions in $G I S, 8(2), 145-154$.

Mousazadeh, H., Keyhani, A., Javadi, A., Mobli, H., Abrinia, K., \& Sharifi, A. 2009. A review of principle and sun-tracking methods for maximizing solar systems output. Renewable and sustainable energy reviews, 13(8), 1800-1818.

Muneer, T. 2007. Solar radiation and daylight models. Routledge.

Pereira, F. O. R., Silva, C. A. N., \& Turkienikz, B. 2001. A methodology for sunlight urban planning: a computer-based solar and sky vault obstruction analysis. Solar energy, 70(3), 217-226.

Š́ri, M., \& Hofierka, J. 2004. A new GIS-based solar radiation model and its application to photovoltaic assessments. Transactions in GIS, 8(2), 175-190.

Š́ri, M., Huld, T. A., Dunlop, E. D., \& Ossenbrink, H. A. 2007. Potential of solar electricity generation in the European Union member states and candidate countries. Solar energy, 81(10), 1295-1305.

Vosselman, G., \& Maas, H. G. 2010. Airborne and terrestrial laser scanning. CRC.

Xu, Z., Guan, X., Jia, Q. S., Wu, J., Wang, D., \& Chen, S. 2012. Performance analysis and comparison on energy storage devices for smart building energy management. IEEE Transactions on Smart Grid, 3(4), 2136-2147.

Revised April 2019 